\title{
Scalp hair patterns in mental subnormality
}

\author{
T. J. DAVID* and CAROLINE M. OSBORNE† \\ Bristol Maternity Hospital
}

\begin{abstract}
Summary. Scalp hair patterns have been examined in 1901 healthy subjects and 1789 severely subnormal patients. Patients with Down's syndrome had a highly significant excess of midline occipital whorls and a deficit of right-sided occipital whorls. Five out of 44 patients with microcephaly had a distinct 'upsweep' of the frontal hair, a much lower proportion than found previously. Patients with unspecified mental subnormality had a highly significant deficit of multiple occipital whorls. Cutis verticis gyrata was noted incidentally in 15 subnormal patients, 13 of whom were males.

Observation of hair patterns in individual patients with mental subnormality is of theoretical interest but is unlikely to be of great practical value.
\end{abstract}

There are as yet few studies of human scalp hair patterns. There is evidence that the number of occipital whorls (usually one or two), the rotation of the whorl (clockwise or anticlockwise), and the location of the whorl or whorls (in the midline or to the right or left of the midline) are all features that are to some extent under genetic control (Lauterbach, 1925; Lauterbach and Knight, 1927; Rife, 1933), though most of the available data are vague. Bernstein (1925) suggested that anticlockwise rotation tended to be dominant to clockwise. Kloepfer (1946-48) found a highly significant parent to offspring correlation for the direction of the whorl. Brewster (1925) published the pedigree of a family showing the occurrence of 'double crowns' for three generations and suggested that the trait was an hereditary character. Recently a useful systematic examination of the distribution and inheritance of human scalp hair patterns in a population sample has been made by four schoolgirls in Cheshire (Charlton et al, 1972). The results clearly confirm that both the number and direction of rotation of scalp patterns are familial traits, the exact mechanisms of inheritance being unclear.

Lauterbach and Knight (1927) and Kiil (1948) suggested that scalp hair patterning may be of medical importance. Recently, Smith and Gong (1973)

\footnotetext{
Received 16 January 1975.

* Present address: Musgrove Park Branch, Taunton and Somerset Hospital, Taunton, Somerset, TA1 5DA.

† Present address: Department of Human Biology, University of Surrey, Guildford, Surrey.
}

have re-examined these suggestions. First, they have found that scalp hair patterns are determined at 10 to 16 weeks of fetal life and are secondary to the growth and shape of tissues which underlie the fetal skin, especially the brain. Secondly, they have produced evidence to show that aberrant scalp hair patterns may be used as a clinical indication of aberrant growth or shape of the early fetal brain before 16 weeks' gestation (Smith and Gong, 1973, 1974). They go on to suggest that aberrant hair patterns, 'may serve as a valuable minor anomaly in the recognition of particular patterns of malformations, as with dermatoglyphics'.

The present study consists of an investigation of scalp hair patterns in a sample of the normal population, and in a sample of patients with mental subnormality. The aim was to investigate possible differences between the scalp hair patterning in these two groups of subjects, and to assess the practical value of looking at hair patterns in subnormal patients.

\section{Subjects and methods}

Occipital hair whorls were classified as follows:

(a) Single or Multiple.

(b) Single whorls-Midline, to the Right or Left of the midline.

(c) Single whorls-Clockwise or Anticlockwise rotation. Clearly the decision as to whether a whorl was midline or not was to some extent arbitrary, but in practice this possible source of confusion caused no difficulty, and in this study most of the subjects were examined by both 
authors. The frontal area was inspected for 'cowslicks' and any signs of an anterior 'upsweep' (see Smith and Gong, 1973), but the observation of these features seemed so subjective that the results have been largely omitted from this paper.

Healthy subjects were obtained by studying unselected children at seven primary schools in the counties of Avon and Somerset. In addition, a group of children admitted to hospital for tonsillectomy were also studied. No attempt was made to exclude more than one member of a family from this study. A special note was made of twins where both were available for study, and an assessment of zygosity was made on the basis of physical findings and dermatoglyphs. No children were excluded from any school visited, and no children in the group of healthy subjects were thought to be mentally subnormal. There were 1050 males and 851 females, giving a total of 1901 healthy subjects.

Severely subnormal patients were obtained by examining unselected in-patients at the Hortham and Stoke Park groups of hospitals for the mentally subnormal in the Avon Area Health Authority. Additional patients with microcephaly were studied at Sandhill Park Hospital, Somerset, and Castle Hill House, Dorset. All patients were divided into the following groups: 1 . Down's syndrome; 2. microcephaly (excluding Down's syndrome); 3. unspecified mental subnormality-cause unknown in most cases; and 4. other identifiable syndromes.

There were 70 patients with other identifiable syndromes, but there were insufficient numbers of any one condition to permit useful analysis of the results. Eighteen patients with Down's syndrome were excluded from study because they were bald or had hair which was too long or too curly to see an occipital hair pattern, leaving 147 patients available for study. Three patients with microcephaly were excluded because they were bald, leaving 44 patients for study. Four hundred and fourteen patients with unspecified mental subnormality were excluded because they were bald or their hair was too long or too curly. This left 625 males and $468 \mathrm{fe}$ males with unspecified mental subnormality for study. The patients' case notes were examined where information was available that might have helped to elucidate the cause of the mental defect.

\section{Results}

Healthy subjects. The results for the healthy subjects, broken down by the separate schools studied, are given in Table $I$. The effect of sex was investigated, and no significant differences were found between the sexes for rotation or location of single whorls. However, males had a significantly higher proportion of multiple whorls: 85/1050 $(8.1 \%)$ compared with $39 / 851(4.6 \%), \chi_{(1)}^{2}$ with Yates' correction $=8.9, \mathrm{P}<0.005$.

The homogeneity of the sample of healthy subjects was examined, taking the rotation, location, and number of whorls separately. There was no significant heterogeneity for the number or rotation of whorls. However, the individual samples (i.e. schools) showed considerable variation for the location of single whorls, and this was found to be statistically significant: $\chi_{(14)}^{2}=34.3, P<0.005$. This could not be attributed to one particular sample, but was a reflection of the overall variation.

The results for the twin-pairs found in the healthy subjects are shown in Table II.

Down's syndrome. The results are shown in Table III, with sexes combined. The patients had a distinct deficit of right whorls, a small deficit of left whorls, and a pronounced excess of midline whorls when compared with the healthy subjects, $\chi_{(2)}^{2}=50.0, P<0.001$. The rotation of single whorls was not significantly affected in patients with Down's syndrome, nor was there a significant difference in the proportion of single and multiple whorls.

Microcephaly. The results are shown in Table III. There were no significant differences when the patients were compared with the healthy subjects for the number, location, or rotation of occipital whorls. In two patients the whorl was

TABLE I

DISTRIBUTION OF HAIR PATTERNS IN HEALTHY SUBJECTS

\begin{tabular}{|c|c|c|c|c|c|c|c|c|}
\hline \multirow{2}{*}{ Group and Sex } & \multicolumn{2}{|c|}{ Right } & \multicolumn{2}{|c|}{ Left } & \multicolumn{2}{|c|}{ Midline } & \multirow{2}{*}{ Multiple } & \multirow{2}{*}{ Total } \\
\hline & C & A & C & $\mathbf{A}$ & C & $\mathbf{A}$ & & \\
\hline $\begin{array}{l}1(M+F) \\
2(M+F) \\
3(M+F) \\
4(M+F) \\
5(M+F) \\
6(M+F) \\
7(M+F) \\
8(M+F) \\
\text { All males } \\
\text { All females } \\
\text { All }(M+F)\end{array}$ & $\begin{array}{r}128(50.2 \%) \\
112(52.6 \%) \\
50(40.3 \%) \\
109(49.1 \%) \\
75(44.9 \%) \\
219(52.0 \%) \\
177(47.1 \%) \\
46(37.4 \%) \\
515(49.0 \%) \\
401(47.1 \%) \\
916(48.2 \%)\end{array}$ & $\begin{array}{c}21(8.2 \%) \\
26(12.2 \%) \\
13(10.5 \%) \\
18(8.1 \%) \\
16(9.6 \%) \\
39(9.3 \%) \\
34(9.0 \%) \\
9(7.3 \%) \\
89(8.5 \%) \\
87(10.2 \%) \\
176(9.3 \%)\end{array}$ & $\begin{array}{c}24(9.4 \%) \\
23(10.8 \%) \\
23(18.5 \%) \\
32(14.4 \%) \\
33(19.8 \%) \\
60(14.3 \%) \\
51(13.6 \%) \\
32(26.0 \%) \\
150(14.3 \%) \\
128(15.0 \%) \\
278(14.6 \%)\end{array}$ & $\begin{array}{r}15(5.9 \%) \\
10(4.7 \%) \\
7(5.6 \%) \\
11(5.0 \%) \\
12(7.2 \%) \\
31(7.4 \%) \\
12(3.2 \%) \\
6(4.9 \%) \\
59(5.6 \%) \\
45(5.3 \%) \\
104(5.5 \%)\end{array}$ & $\begin{array}{c}37(14.5 \%) \\
28(13.1 \%) \\
19(15.3 \%) \\
32(14.4 \%) \\
22(13.2 \%) \\
44(10.5 \%) \\
59(15.7 \%) \\
11(8.9 \%) \\
127(12.1 \%) \\
125(14.7 \%) \\
252(13.3 \%)\end{array}$ & $\begin{array}{r}9(3.5 \%) \\
8(3.8 \%) \\
3(2.4 \%) \\
4(1.8 \%) \\
1(0.6 \%) \\
7(1.7 \%) \\
11(2.9 \%) \\
8(6.5 \%) \\
25(2.4 \%) \\
26(3.1 \%) \\
51(2.7 \%)\end{array}$ & $\begin{array}{r}21(8.2 \%) \\
6(2.8 \%) \\
9(7.3 \%) \\
16(7.2 \%) \\
8(4.8 \%) \\
21(5.0 \%) \\
32(8.5 \%) \\
11(8.9 \%) \\
85(8.1 \%) \\
39(4.6 \%) \\
124(6.5 \%)\end{array}$ & $\begin{array}{r}255 \\
213 \\
124 \\
222 \\
167 \\
421 \\
376 \\
123 \\
1050 \\
851 \\
1901\end{array}$ \\
\hline
\end{tabular}

Each group represents a different school. Group 3 is the group of children in hospital for tonsillectomy.

$\mathbf{C}=$ Clockwise $; \quad \mathbf{A}=$ Anticlockwise $; \quad \mathbf{M}=$ Male $; \quad \mathbf{F}=$ Female. 
TABLE II

LOCATION AND ROTATION OF WHORLS IN TWINS (HEALTHY SUBJECTS)

\begin{tabular}{|c|c|c|c|}
\hline Zygosity & Twin $a$ or $b$ & Sex & Hair Pattern \\
\hline$M Z$ & $\begin{array}{l}\mathrm{a} \\
\mathrm{b}\end{array}$ & $\underset{F}{F}$ & $\begin{array}{l}\mathrm{RC} \\
\mathrm{RC}\end{array}$ \\
\hline$M Z$ & $\begin{array}{l}\mathrm{a} \\
\mathrm{b}\end{array}$ & $\underset{\mathrm{F}}{\mathrm{F}}$ & $\begin{array}{l}\text { RA } \\
\text { LC }\end{array}$ \\
\hline$M Z$ & $\begin{array}{l}\mathbf{a} \\
\mathrm{b}\end{array}$ & $\begin{array}{l}M \\
M\end{array}$ & $\begin{array}{l}\text { RC } \\
\text { LC }\end{array}$ \\
\hline $\mathrm{DZ}$ & $\begin{array}{l}a \\
b\end{array}$ & $\underset{F}{F}$ & $\begin{array}{l}\mathrm{LC}+\mathrm{RA}^{*} \\
\mathrm{LC}+\mathrm{RC}^{*}\end{array}$ \\
\hline $\mathrm{Dz}$ & $\begin{array}{l}a \\
b\end{array}$ & $\underset{\mathrm{F}}{\mathrm{F}}$ & $\begin{array}{l}\mathrm{RC} \\
\mathrm{RC}\end{array}$ \\
\hline $\mathrm{DZ}$ & $\underset{b}{a}$ & $\underset{\mathrm{F}}{\mathrm{F}}$ & $\underset{L C}{R C}$ \\
\hline $\mathrm{DZ}$ & $\underset{b}{a}$ & $\underset{F}{F}$ & $\begin{array}{l}\mathrm{RC} \\
\mathrm{MC}\end{array}$ \\
\hline $\mathrm{DZ}$ & $\underset{b}{a}$ & $\underset{F}{F}$ & $\stackrel{\mathrm{RC}}{\mathrm{LC}}+\mathrm{MA}^{*}$ \\
\hline $\mathrm{DZ}$ & $\begin{array}{l}\mathrm{a} \\
\mathrm{b}\end{array}$ & $\underset{\mathbf{F}}{\mathbf{F}}$ & $\underset{\text { LC }}{\mathrm{LC}}$ \\
\hline $\mathrm{DZ}$ & $\begin{array}{l}\text { a } \\
\text { b }\end{array}$ & $\stackrel{M}{M}$ & $\begin{array}{l}\mathrm{MC} \\
\mathbf{L C}+\mathrm{RA}^{*}\end{array}$ \\
\hline $\mathrm{DZ}$ & $\begin{array}{l}\mathbf{a} \\
\mathrm{b}\end{array}$ & $\stackrel{M}{M}$ & $\begin{array}{l}\mathrm{LC} \\
\mathrm{RC}\end{array}$ \\
\hline $\mathbf{D z}$ & $\begin{array}{l}\mathrm{a} \\
\mathrm{b}\end{array}$ & $\begin{array}{l}M \\
M\end{array}$ & $\begin{array}{l}\mathrm{RC} \\
\mathrm{RA}\end{array}$ \\
\hline $\mathrm{DZ}$ & $\begin{array}{l}a \\
b\end{array}$ & $\underset{\mathrm{M}}{\mathrm{F}}$ & $\begin{array}{l}\text { RC } \\
\text { LC }\end{array}$ \\
\hline
\end{tabular}

Symbols: $R C=$ right clockwise; $R A=$ right anticlockwise; $M C=$ midline clockwise; $M A=$ midline anticlockwise; $L A=$ left clockwise; * double whorl.

noted to be placed more anteriorly than usual. In five patients there was a distinct 'upsweep' of the hair in the midline in the frontal area.

Unspecified mental subnormality. The results for females and males are shown in Table III. There were no significant differences between patients and healthy subjects for rotation of single whorls. Both male and female patients showed the same trends in the location of single whorls, which was an increase in the proportion of left whorls accompanied by a reduction in the proportion of right whorls. The proportion of midline whorls was very similar when the patients were compared with the healthy subjects of the same sex. In the males, the distribution of location of single whorls was significantly different from the healthy subjects, $\chi_{(2)}^{2}=9.5, P<0.01$. In the females the difference did not quite reach statistical significance, $\chi_{(2)}^{2}=5.2$. Patients of both sexes had a highly significant deficit of multiple whorls when compared with healthy subjects (males $\chi_{(1)}^{2}$ with Yates' correction $=44.1$, $P<0.001$; females $\chi_{(1)}^{2}$ with Yates' correction $=12.2$, $\mathrm{P}<0.001)$.

Cutis verticis gyrata. Though not specially looked for, 13 males and two females out of the 1789 patients with mental subnormality had this scalp anomaly. Seven of the males with cutis verticis gyrata were bald, making the defect much more easily visible. Of the 15 patients with cutis verticis gyrata, one had arrested hydrocephalus, one had tuberous sclerosis, one had microcephaly, and one was blind with left microphthalmos. The rest had unspecified mental subnormality. None of the healthy subjects was noted to have cutis verticis gyrata.

\section{Discussion}

In the healthy subjects, males had significantly more multiple whorls than females, but apart from this difference sex apparently has little influence on the occipital hair pattern. The sex difference for multiple whorls has been noted previously (Lauterbach and Knight, 1927). The different schools studied appear to comprise a fairly homogeneous group of subjects, though there was significant variation in the location of single whorls between the different schools. The explanation for this variation is not evident from the data. A large

TABLE III

DISTRIBUTION OF HAIR PATTERNS IN SUBNORMAL PATIENTS

\begin{tabular}{|c|c|c|c|c|c|c|c|c|}
\hline \multirow{2}{*}{ Group and Sex } & \multicolumn{2}{|c|}{ Right } & \multicolumn{2}{|c|}{ Left } & \multicolumn{2}{|c|}{ Midline } & \multirow{2}{*}{ Multiple } & \multirow{2}{*}{ Total } \\
\hline & C & $\mathbf{A}$ & C & A & C & A & & \\
\hline $\begin{array}{l}\text { Down's syndrome } \\
\text { (M+F) } \\
\text { Microcephaly }(\mathbf{M}+\mathbf{F}) \\
\text { Unspecified } \\
\text { subnormality } \\
\text { (females) } \\
\text { Unspecified } \\
\text { subnormality (males) }\end{array}$ & $\begin{array}{l}37(25.2 \%) \\
21(47.7 \%) \\
192(41.0 \%) \\
282(45.1 \%)\end{array}$ & $\begin{array}{r}19(12.9 \%) \\
5(11.4 \%) \\
57(12.2 \%) \\
65(10.4 \%)\end{array}$ & $\begin{array}{r}24(16.3 \%) \\
6(13.6 \%) \\
84(17.9 \%) \\
132(21.1 \%)\end{array}$ & $\begin{array}{l}5(3.4 \%) \\
4(9.1 \%) \\
35(7.5 \%) \\
43(6.9 \%)\end{array}$ & $\begin{array}{r}48(32.7 \%) \\
6(13.6 \%) \\
80(17.1 \%) \\
81(13.0 \%)\end{array}$ & $\begin{array}{c}10(6.8 \%) \\
0 \\
16(3.4 \%) \\
19(3.0 \%)\end{array}$ & $\begin{array}{l}4(2.7 \%) \\
2(4.5 \%) \\
4(0.9 \%) \\
3(0.5 \%)\end{array}$ & $\begin{array}{r}147 \\
44 \\
\\
468 \\
625\end{array}$ \\
\hline
\end{tabular}

$\mathrm{C}=$ Clockwise $; \quad \mathrm{A}=$ Anticlockwise $; \quad \mathrm{M}=$ Males $; \mathrm{F}=$ Females 
difference for location of single whorls was exhibited between groups 7 and 8 (see Table I), but these groups were two schools only five miles apart. Clearly, in theory, this variation might have a genetic basis, and this aspect of the distribution of hair patterns could usefully be studied further. The practical implication is that any differences between a group of healthy subjects and a group of patients of no greater magnitude than the variation within healthy subjects should be regarded with great caution.

There were 13 twin-pairs among the healthy subjects. Only three of these pairs were monozygotic, and two of these were discordant for the type of hair pattern. The sample of twins is a little odd in that there are twice as many female twins as male twins (though there were more males than females in the whole group of healthy subjects), and only one pair of unlike-sexed twins. Mirror-imaging of hair patterns in monozygotic twins was noted by Lauterbach (1925) and by Rife (1933), but it was only observed in one of the three monozygotic sets (and none of the dizygotic sets) in this study.

The patients with Down's syndrome showed a highly significant excess of midline whorls when compared with healthy subjects, this excess being accompanied by a deficit of right-sided whorls. This finding does not appear to have been noted before, Smith and Gong (1973) merely commenting on some anterior displacement of the whorl in some cases which was not observed in the present study. Whether the excess of midline whorls is a 'genetic' consequence of an extra chromosome or an indicator of aberrant growth is a matter of speculation.

Smith and Gong (1973, 1974) held out great hopes that scalp hair patterning might provide an important clue to the timing of the defect in severe microcephaly. They found that $85 \%$ of patients with microcephaly (20 patients were studied) had altered scalp hair patterning, and that in particular $25 \%$ had no occipital whorl at all (a feature which they had only noted in nonhuman primates). The present study did not confirm these previous results. All 44 patients with microcephaly had an occipital whorl. A pronounced 'upsweep' of the hair in the frontal area was noted in five cases, a feature that was said to be present in most of Smith and Gong's patients. Whether scalp hair patterns will be of practical use in microcephaly remains to be seen.

The patients with unspecified mental subnormality provided some unexpected results. The differences in location of single patterns between healthy subjects and patients just reached significance in the males but did not quite do so in the females. In view of the variation of this feature in healthy subjects this finding must await confirmation. However, patients of both sexes showed a highly significant deficit of multiple whorls. Why this should be so is far from clear.

Cutis verticis gyrata was noted incidentally during this study in 15 out of 1789 subnormal patients $(0.8 \%)$, and the male preponderance was as striking as in other series (Paulson and Dudley, 1966; MacGillivray, 1967; Warkany, 1971; Paulson, 1974). Seven of the 13 males were bald which clearly rendered ascertainment of this defect more likely, but this cannot be the whole explanation of the well-known male preponderance.

In conclusion, it seems that observation of hair patterns in individual patients with mental subnormality is of theoretical interest but is unlikely to be of great practical value, though further work might be useful. A knowledge of the nature of the inheritance of scalp hair patterns in man would be aided by studies of other population samples and by family studies. The study of hair patterns, or 'trichoglyphics' as it has been called (Smith and Gong, 1974), is still in its infancy.

We are indebted to $\mathrm{Mr} \mathrm{A}$. Downes and Dr D. F. Roberts for their help; to the physicians who permitted the study of their patients, and to the teachers who permitted the study of their schoolchildren; and to Miss G. K. Walker, Biology Teacher at the Prenton High School for Girls, Birkenhead, for lending us the results of the Cheshire study.

\section{REFERENCES}

Bernstein, F. (1925). Cited by Kloepfer (1946-48).

Brewster, E. T. (1925). The inheritance of 'double crown'. Fournal of Heredity, 16, 345-346.

Charlton, J., Johnson, S., Lomax, K., and Pritchard, C. (1972). The inheritance of crown and nape patterns in human scalp hair. Project which appeared on BBC television 'Young Scientists of the Year' (unpublished).

Kiil, V. (1948). Frontal hair direction in mentally deficient individuals. Fournal of Heredity, 39, 281-285.

Kloepfer, H. W. (1946-48). An investigation of 171 possible linkage relationships in man. Annals of Eugenics, 13-14, 35-71.

Lauterbach, C. E. (1925). Studies in twin resemblance. Genetics, $10,525-568$.

Lauterbach, C. E. and Knight, J. B. (1927). Variation in whorl of the head hair. Fournal of Heredity, 18, 107-115.

MacGillivray, R. C. (1967). Cutis verticis gyrata and mental retardation. Scottish Medical fournal, 12, 450-454.

Paulson, G. W. (1974). Cutis verticis gyrata and the Lennox syndrome. Developmental Medicine and Child Neurology, 16, 196200.

Paulson, G. and Dudley, A. W. (1966). Cutis verticis gyrata (CVG). Confinia Neurologica, 28, 432-442.

Rife, D. C. (1933). Genetic studies of monozygotic twins. III Mirror-imaging. Fournal of Heredity, 24, 443-446.

Smith, D. W. and Gong, B. T. (1973). Scalp hair patterning as a clue to early fetal brain development. Fournal of Pediatrics, 83, 374-380.

Smith, D. W. and Gong, B. T. (1974). Scalp-hair patterning: its origin and significance relative to early brain and upper facial development. Teratology, 9, 17-34.

Warkany, J. (1971). Congenital Malformations, pp. 1192-1193. Year Book Medical Publications, Chicago. 